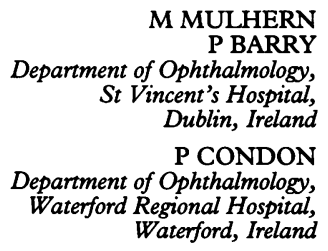

Correspondence to: $\mathrm{Mr}$ M Mulhern.

Accepted for publication 17 October 1995

1 John ME, Noblitt RI, Boleyn KL, Raanan MG, De Luca BS. Effect of superficial and deep scleral pocket incisions on the incidence of hyphema. I Cataract Refract Surg 1992; 18:

2 Sparks GM. Descemetopexy. Surgical reattachment of stripped Descemet's membrane. Arch Ophthalmol 1967; 78: 31-4.

3 Anderson CJ. Gonioscopy in no-stitch cataract incisions. $\mathcal{f}$ Cataract Refract Surg 1993; 19: 620-1.

4 Wong VK, Koenig SB, Fogel ES, Freedman MI. Late detachment of Descemet's membrane after subconjunctival THC:YAG (holmium) laser thermal sclerostomy (ab externo). $A m \mathcal{F}$ Ophthalmol 1993; 116: 514-5.

5 Macsai MS. Total detachment of Descemet's membrane after small incision cataract extracmembrane after small incision cataract ext

6 Minkovitz JB, Schrenk LC, Pepose JS. Minkovitz JB, Schrenk LC, Pepose JS.
Spontaneous resolution of an extensive detachment of Descemet's membrane following phacoemulsification. Arch Ophthalmol 1994; 112: 551-2.

7 Vastine DW, Weinberg RS, Sugar J, Binder PS. Stripping of Descemet's membrane associated with intraocular lens implantation. Arch Ophthalmol 1983; 101: 1042-5.

8 Mackool RJ, Holtz SJ. Descemet's membrane detachment. Arch Ophthalmol 1977; 95: 459-63.

\section{Acute posterior multifocal placoid pigment epitheliopathy associated with pulmonary tuberculosis}

EDITOR,-The hallmark of acute posterior multifocal placoid pigment epitheliopathy (APMPPE) is the appearance of multiple discrete cream-coloured lesions with ill defined margins concentrated in the posterior pole and deep within the retina. The condition has recently been reviewed ${ }^{1}$ and has been associated with a wide range of disorders. These include adenovirus type 5 infection, ${ }^{2}$ vaccination for swine flu, ${ }^{3}$ cerebral vasculitis, ${ }^{4}$ Lyme disease, ${ }^{5}$ sarcoidosis, ${ }^{6}$ photic damage to the retina, ${ }^{7}$ and lead toxicity. ${ }^{8}$ We report a patient presenting with a clinical picture of APMPPE in whom asymptomatic lung infection by tuberculosis was also identified.

\section{CASE REPORT}

A 34-year-old woman reported to an ophthalmic casualty department with a history of progressive blurring of vision of the left eye over the previous 24 hours. Systemic inquiry was otherwise negative. There were no respiratory symptoms. She was married with an 8-month-old child, and had never smoked cigarettes. General physical examination was normal. Visual acuities were $6 / 60$ left eye and $6 / 5$ right eye. Multifocal lesions of pale yellow appearance with indistinct margins were found on retinal examination of the left eye (Fig 1). These lesions were positioned within the vascular arcades with other smaller peripheral lesions. Fluorescein angiography showed early masking with late fluorescence.

The chest radiograph exhibited a round 2 $\mathrm{cm}$ lesion in the right middle third of the lung field. Subsequent computerised tomography showed the lesion to be in the right lower lobe. It was clearly defined with no evident calcification. The mediastinum was normal.

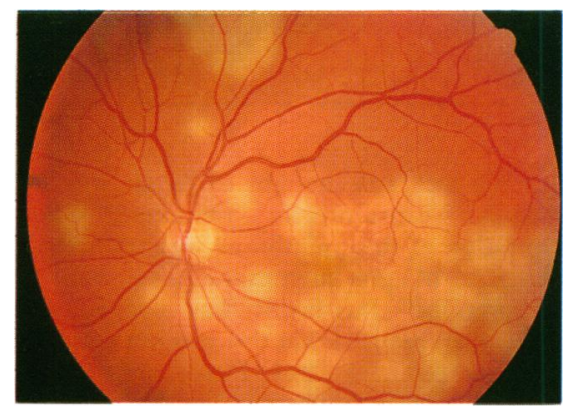

Figure 1 Left fundus appearance on presentation showing multifocal pale yellow lesions with indistinct margins.

A tuberculin test (1/1000) produced $25 \mathrm{~mm}$ induration. There was no scar on any of the usual vaccination sites to suggest previous BCG. Haemoglobin was $14.8 \mathrm{~g} / \mathrm{dl}$, white cell count $6.2 \times 10^{9} / 1$ with normal differential count, erythrocyte sedimentation rate was 18 $\mathrm{mm}$ in the first hour. Serum electrolytes, creatinine, calcium, phosphate, glucose, liver function tests, albumin, and urate were normal as were serum angiotensin, antinuclear factor, rheumatoid factor, and syphilis serology.

Pulmonary tuberculosis was suspected and treated with isoniazid, rifampicin, and pyrazinamide. One month later she developed a productive cough. Numerous acid and alcohol fast bacilli were seen on direct microscopy of the sputum but these did not grow on culture medium during 16 weeks of incubation. The non-viability of these organisms presumably resulted from antituberculous treatment. Her lung shadow subsequently cleared in a manner typical of early tuberculosis which fully resolves with appropriate therapy.

From the respiratory aspect, her health remains excellent and she successfully completed her planned 6 month course of antituberculous therapy. Progressive pigmentation of the fundal lesions took place (Fig 2) and in this case there has been no significant improvement in vision.

\section{COMMENT}

We are not aware of any previous case published in which the clinical appearance of APMPPE has been associated with otherwise asymptomatic infection by tuberculosis.

The alternative diagnostic label of multifocal choroiditis could, of course, be applied but in the case described it was a clinical appearance indistinguishable from APMPPE which led to the systemic diagnosis.

The clinical features on presentation of our patient accord with those typical of APMPPE. 9 Our patient was young. Her

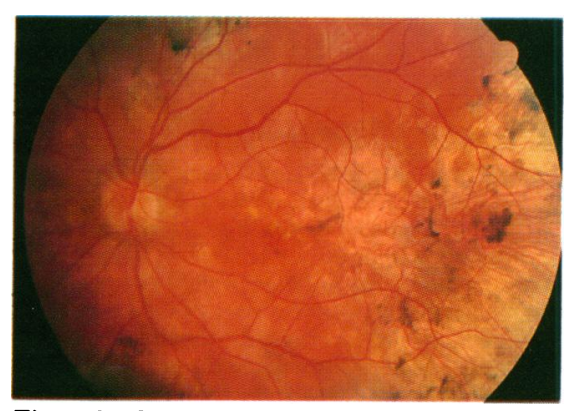

Figure 2 Left fundus appearance following resolution of acute lesions. Extensive areas of retinal pigment epithelial atrophy and pigment clumping are seen. visual symptoms were of rapid onset and she developed 'multiple postequatorial, circumscribed, flat, grey-white, subretinal lesions involving the RPE'9 on examination by biomicroscopy and fluorescein angiography. The late features of the disorder in our patient accord with those described for APMPPE ${ }^{9}$ but also resemble those of other white spot syndromes $^{10}$ in which the spots are of larger size and tend to coalesce.

It is of interest that in the original description of APMPPE by Gass, ${ }^{11}$ of the four cases described, two had a positive tuberculin skin test and one a family history of TB although none had overt tuberculosis. This patient's case (which has now been formally notified on the TB register) highlights that patients with the clinical appearance of APMPPE warrant careful investigation for underlying tuberculosis.

K ANDERSON
K R PATEL
Department of Respiratory Medicine,
Western Infirmary, Glasgow
L WEBB
G N DUTTON
Department of Ophthalmology,
Western Infirmary, Glasgow

Correspondence to: Dr L A Webb, Department of Ophthalmology, Western Infirmary, Dumbarton Road, Glasgow G11 6NT.

Accepted for publication 20 September 1995

1 Jones NP. Acute posterior multifocal placoid pigment epitheliopathy. Br f Ophthalmol 1995; 79: 384-9.

2 Azar P Jr, Gohd RS, Waltman D, Gitter KA. Acute posterior multifocal placoid pigment epitheliopathy associated with an adenovirus type 5 infection. Am $\mathcal{F}$ Ophthalmol 1975; 80: 1003-5.

3 Hector RE. Acute posterior multifocal placoid pigment epitheliopathy. Am $\mathcal{f}$ Ophthalmol 1978; 86: 424-5.

4 Sigelman J, Behrens M, Hilal S. Acute posterior multifocal placoid pigment epitheliopathy associated with cerebral vasculitis and homonymous hemianopia. Am $\mathcal{F}$ Ophthalmol 1979; 88: 919-24.

5 Bodine SR, Marino J, Camisa TJ, Salvate AJ. Multifocal choroiditis with evidence of Lyme disease. Ann Ophthalmol 1992; 24: 169-73.

6 Dick DJ, Newman PK, Richardson J, Wilkinson $\mathrm{R}$, Morley AR. Acute posterior multifocal placoid pigment epitheliopathy and sarcoidosis. Br f Ophthalmol 1988; 72: 74-7.

7 Henkes HE. Photic injury to the retina and the manifestation of acute posterior multifocal placoid pigment epitheliopathy. Doc Ophthalmol 1977; 44: 113-20.

8 Schubert HD, Lucier AC, Bosley TM. Pigmentary epitheliopathy, disc edema, and lead intoxication. Retina 1988; 8: 154-7.

9 Gass JDM. Stereoscopic atlas of macular disease, diagnosis and treatment. 3rd ed. St Louis: CV Mosby, 1987.

10 Ben Ezra D, Forrester JV. Fundal white dots: the spectrum of a similar pathological process. Br f Ophthalmol 1995; 79: 856-60.

11 Gass JDM. Acute posterior multifocal placoid pigment epitheliopathy. Arch Ophthalmol 1968; 80: 177-85.

\section{Disappearance of optociliary shunt} vessels after optic nerve sheath decompression

EDITOR,-Optociliary shunt vessels were described by Salzman in 1893 and have been reported in association with many ophthalmic conditions including central retinal vein occlusion, optic nerve sheath meningioma, and chronic papilloedema. The common mechanism appears to be obstruction to blood outflow in the central retinal vein which results in shunts between retinal and choroidal veins, usually at the edge of the optic disc. We report a patient with otitic hydrocephalus causing chronic papilloedema associated with optociliary shunts which resolved after optic nerve 